\title{
FLUID DYNAMIC AND ACOUSTIC OPTIMIZATION METHODOLOGY OF A FORMULA-STUDENT RACE CAR ENGINE EXHAUST SYSTEM USING MULTILEVEL NUMERICAL CFD MODELS
}

\author{
Barhm MOHAMAD ${ }^{1}$, Mohammed Qasim ALI ${ }^{2}$, Hayder Ahmed NEAMAH ${ }^{3,4}$, Andrei ZELENTSOV ${ }^{5}$, \\ Salah AMROUNE ${ }^{6}$ \\ ${ }^{1}$ Faculty of Mechanical Engineering and Informatics, University of Miskolc, 3515 Miskolc-Hungary \\ ${ }^{2}$ Vocational Education Department, Ministry of Education, Babel, Iraq \\ ${ }^{3}$ School of Automotive Engineering, Wuhan University of Technology, Wuhan, 430070, P. R. China. \\ ${ }^{4}$ Ministry of Oil, Midland Oil Company, Baghdad, Iraq \\ ${ }^{5}$ Piston Engine Department, Bauman Moscow State Technical University, 105005 Moscow-Russia \\ ${ }^{6}$ Université Mohamed Boudiaf; B.P 166 ICHBELIA M'sila 28000, Algérie.
}

Abstract

In this work a multilevel CFD analysis have been applied for the design of an engine exhaust system include manifold and muffler with improved characteristics of noise reduction and fluid dynamic response. The approaches developed and applied for the optimization process range from the 1D to fully 3D CFD simulation, exploring hybrid approaches based on the integration of a 1D model and 3D tools.

Once the best configuration has been defined, the 1D-3D approach has been adopted to confirm the prediction carried out by means of the simplified approach, studying also the impact of the new configuration on the engine performances.

Keywords: Engine performance, sound pressure level, computational fluid dynamics, modeling and simulation, exhaust system

\section{INTRODUCTION}

The control of both the level and quality of internal combustion engine noise is a key aspect of the design process of a new vehicle powertrain system, in order to satisfy the legislation limits and provide a characteristic exterior sound. In particular, the gas dynamic noise is radiated from the engine intake and exhaust duct systems due to the highly unsteady flows in the pipes, originated by the periodic cylinder gas exchange process (Cengel and Boles 2007). The attenuation of gas dynamic noise relies on suitable reactive, dissipative and hybrid mufflers with simple and complex geometries, designed and optimized to damp or emphasize certain spectral components of the engine noise [Mohamad 2019]. The objective of this study is to show new techniques for design and optimization of engine exhaust parts include exhaust manifold and the muffler. Mohamad et al 2017 Studied the blending fuels technique to improve the combustion in internal combustion engines, the comparison has done for the effects of dual alcohols (methanol and ethanol) blended in gasoline fuel (GF) against performance, combustion and emission characteristics. The results show that indicate thermal efficiency (ITE) improved whereas the exhaust gas temperature (EGT) of the blends reduced, which is a benefit that reduces compression work. Mohamad and
Zelentsov 2019 Used developed integrating the 1D code with the CFD AVL Fire code. The strategy adopted for the coupling of the two codes were described in their studies. Montenegro and Onorati 2009 Present general non-linear approach to calculate and validate transmission loss prediction of a muffler in presence of the sound absorbing material by applying modified conservation equations of a multidimensional solver. Harrison and Stanev Used simplified linear acoustic model to calculate pressure time-depended in the intake manifold of an IC engine, their model has proved useful in identifying the role of pipe resonance in the intake process and has led to explain the structure of the intake pressure time-depended.

\section{NUMERICAL APPROACH DESCRIPTION}

Both acoustics and turbulence, although they are very different in many ways, are governed by the same basic equations of fluid motion usually known as the Navier-Stokes equations:

$$
\begin{aligned}
\rho\left[\frac{\partial w_{i}}{\partial t}+w j \frac{\partial w_{i}}{\partial x_{i}}\right]+\frac{\partial P}{\partial x_{i}}-\frac{\partial \tau_{i j}}{\partial x_{j}}=0 ; \\
{\left[\frac{\partial \rho}{\partial t}+\frac{\partial \rho}{\partial x_{j}}\right]+\rho \frac{\partial w_{j}}{\partial x_{j}}=0 . }
\end{aligned}
$$


These are equations of momentum and continuity, written in tensor notation. Density and pressure have symbols $\rho$ and $\mathrm{P}$. The vectors for position and velocity are denoted by $\mathrm{x}_{\mathrm{i}}$ and $\mathrm{w}_{\mathrm{i}}$ respectively where the index $\mathrm{i}=1,2$ or 3 , corresponding to the three Cartesian axes, so that first term is actually three equations, found by setting $\mathrm{i}$ to each of its values. The term $\tau_{\mathrm{ij}}$ is the viscous stress tensor and will turn out to be very important in the study of turbulence. Tensor notation is often a much more compact way of writing the equations of fluid motion, and you should be able to switch between it and vector notation.

The system of transport equations in the Reynolds form is closed by the $k-\zeta-f$ turbulence model. This model was specially developed for the processes of flow, combustion, and heat transfer in piston engines. $k-\zeta-f$ model has three equations: for the $k$ kinetic energy of turbulence, for the $\varepsilon$ dissipation rate of this energy known from the $\mathrm{k}-\varepsilon$ model of turbulence, and the equations for the normalized velocity scale $\zeta=\bar{W}^{2} / k$ (Hanjalič et al 2004). Hybrid wall functions were used to determine parameters of gas flow and heat transfer into the boundary layer.

The sound pressure level (SPL) is defined to be:

$$
S P L=20 \log \frac{P^{\sim-P^{\sim}} r e f}{2 \times 10^{-5}(P a)}
$$

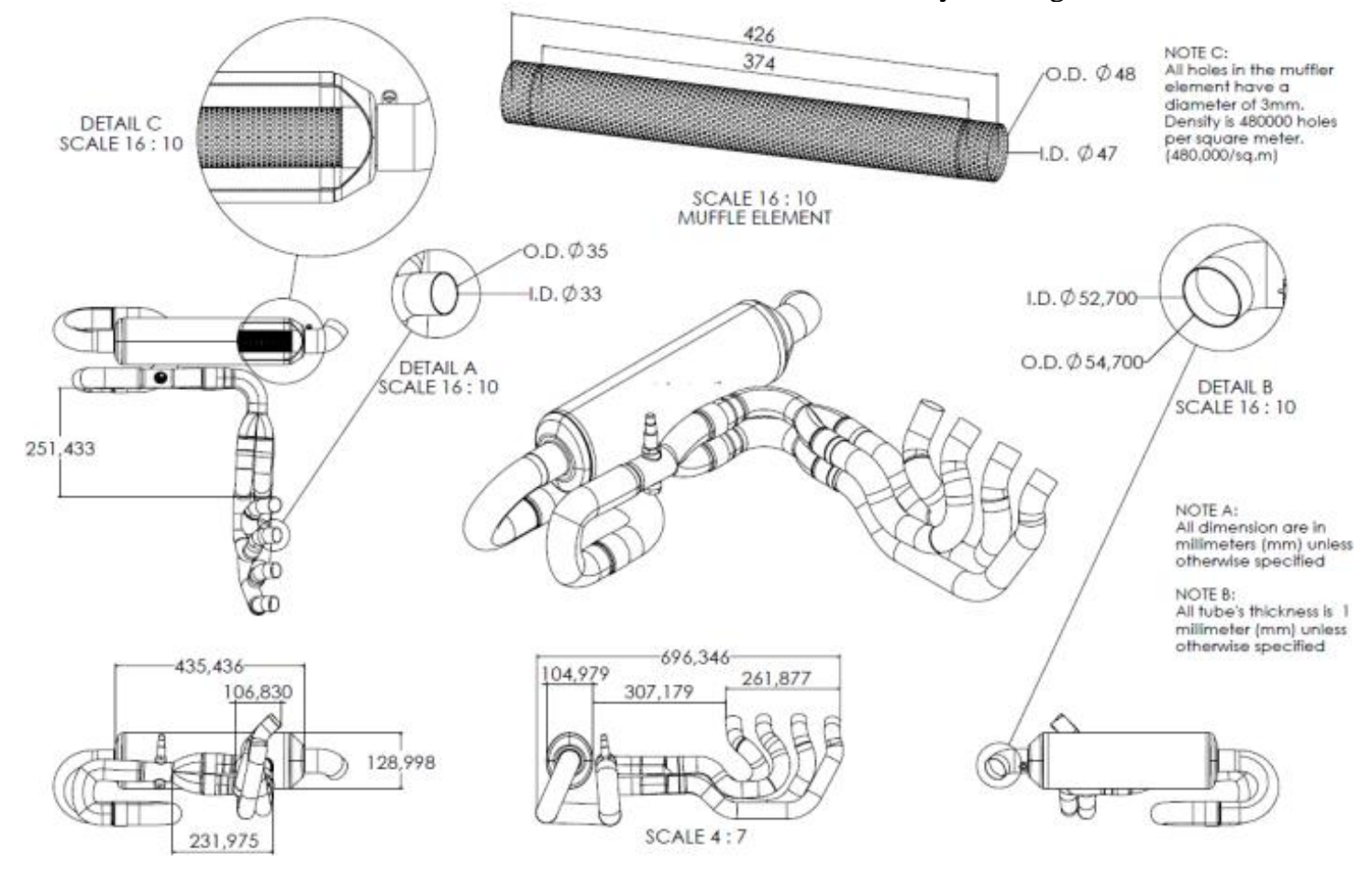

Fig. 1. The cross section and dimensions of the exhaust system [Mohamad et al 2020].
Where $P^{\sim}-P^{\sim}{ }_{\text {ref }}=\left(P^{\sim}\right)$ is referred as sound pressure and $P^{\sim}$ ref is a reference pressure defined as:

$$
\mathrm{P}_{\text {ref }}^{\sim}(\mathrm{x}, \mathrm{y})=\frac{1}{T} \int_{0}^{T} P^{\sim}(x, y, t) d t
$$

Where $\mathrm{T}$ is the period of a time cycle.

An ideal tube length of the exhaust system (manifold), L (m) is inversely proportional to the engine speed, $\mathrm{n}$ (rpm) with respective to the constant acoustic speed, a $(\mathrm{m} / \mathrm{s})$ as explained in Equation 4 [Richard, 2004]:

$$
L \approx \frac{(10 \times a)}{n}
$$

\section{SOFTWARE SETUP}

The geometry was implemented based on current FS exhaust system prototype using SolidWorks 2017 advanced design software, including exhaust manifold and muffler. The perforate pipe was placed in the middle of the cylindrical shaped chamber of the muffler as show in figure 1. The dimensions and data of the exhaust system was inserted to the software in order to simulate, details in figure 2 .

The BOOST program package consists of an interactive pre-processor which assists with the preparation of the input data for the main calculation program (Bosch 2009) and (AVL BOOST 2011), the engine was sketch up and tested successfully as in figure 3 . 


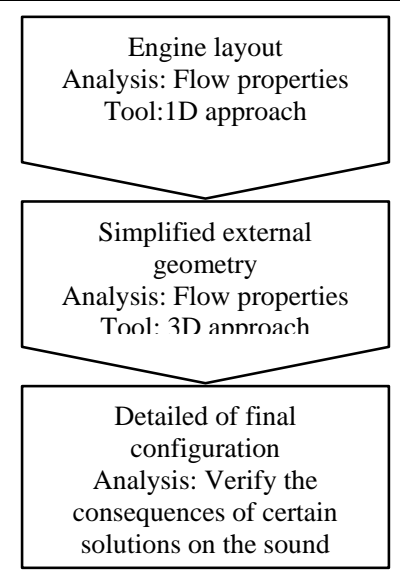

Fig.2. Flowchart of the design and an optimization process

The term 1D model implies a one-dimensional approach to the description of processes in the exhaust systems of the piston engine. The onedimensional statement of the problem allows estimating the influence of pipelines and channels dimensions (diameters, lengths, fillet radii) on the gas flow.
At the same time, despite the name "onedimensional model", the processes inside the cylinder are considered in the zero-dimensional formulation. With this approach, the entire cylinder (section) is considered as a single volume in which the processes of intake, compression, combustion, expansion and outlet occur. This volume, unlike the three-dimensional approach, is not divided into subdomains (control or finite volumes). The system of equations (energy, continuity, gas state) is written only for one volume that changes with time (in the three-dimensional approach - the system of equations is solved for each control volume).

It is based on the solution of multiple local Favré-Reynolds stress closures for compressible flows, each one centered on a face constituting the boundary patch which interfaces the 1D domain with the 3D one (Adumitroaie et al 1999). This approach allows to locate the 1D-3D interface even in regions close to highly 3D shapes, therefore allowing the treatment of non-uniform fields on the 3D side without compromising the stability of the solution.

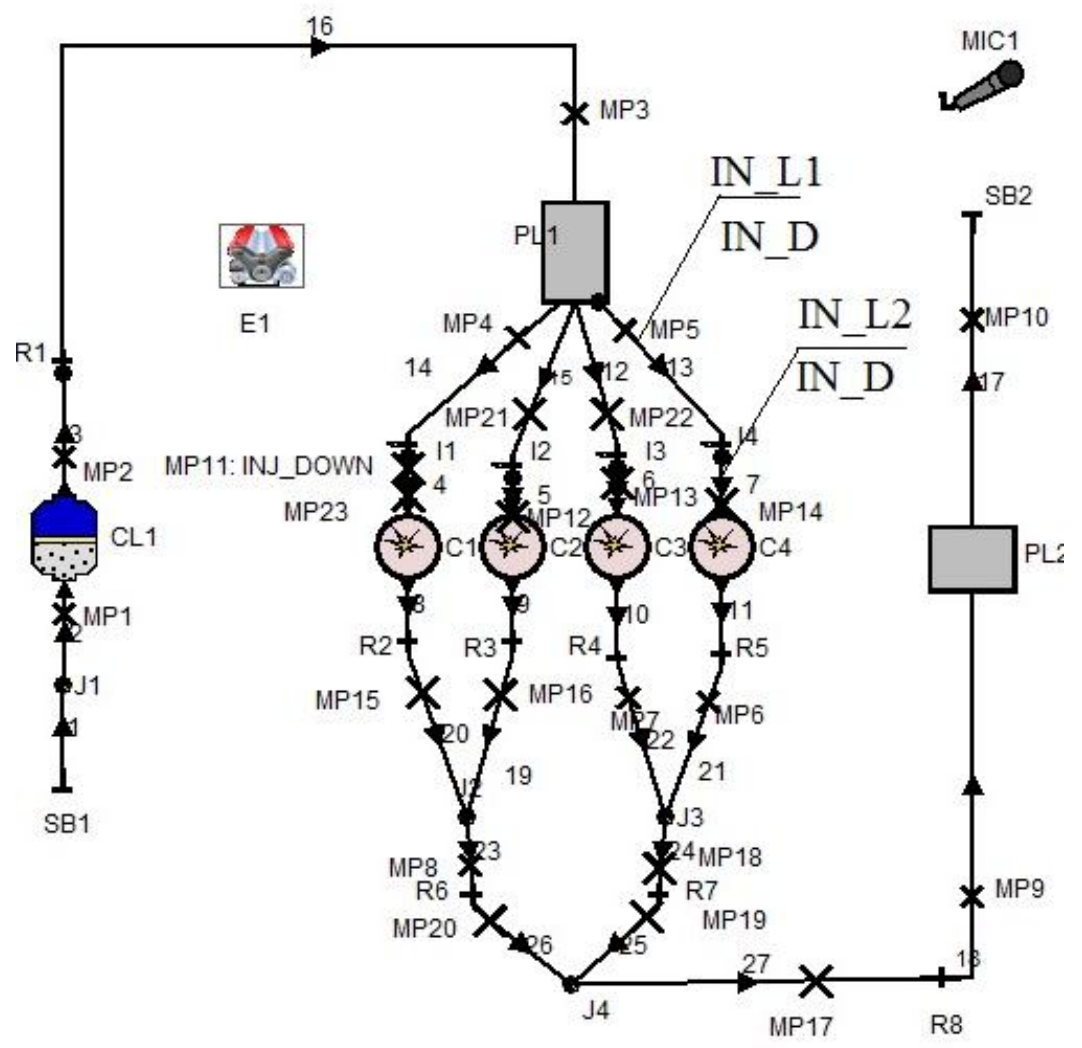

Fig. 3. 1D model of the Honda CBR 600RR (PC 37) engine: volume of plenum (PL1), intake ports length and diameter (IN_L1, IN_L2, IN_D), [Mohamad et al 2019]. 


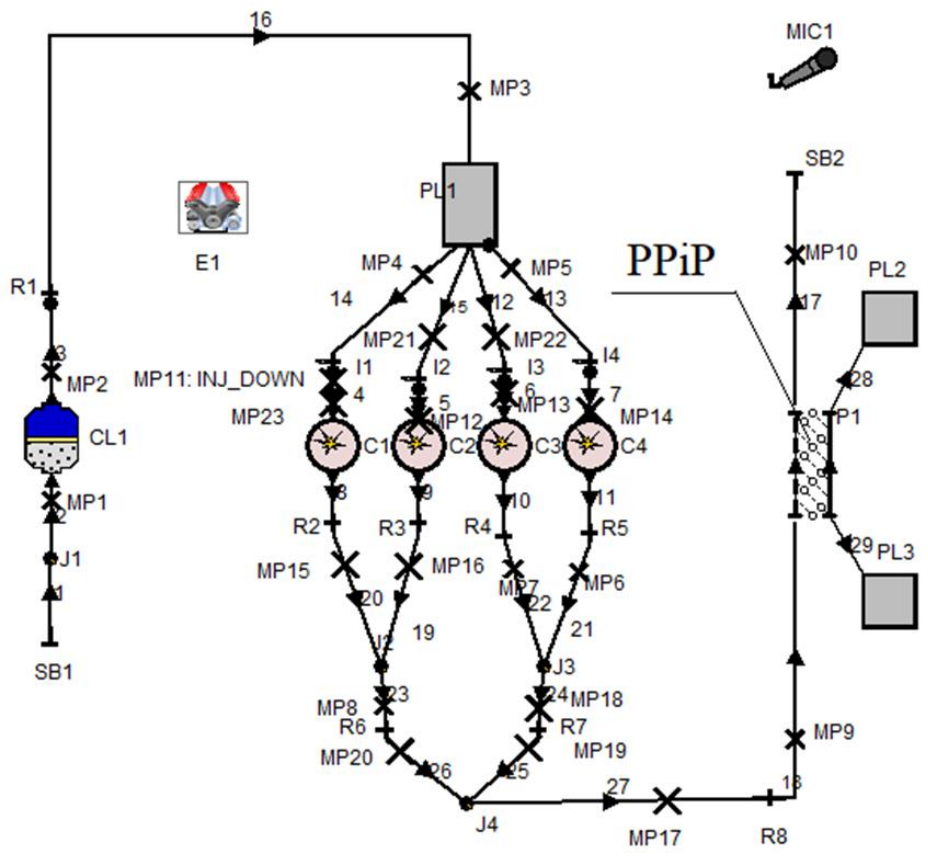

Fig. 4. Engine scheme: modified parameters - volume of PPiP, exhaust ports include length (Lm) and (Dm) diameter of muffler chamber, [Mohamad et al 2020].

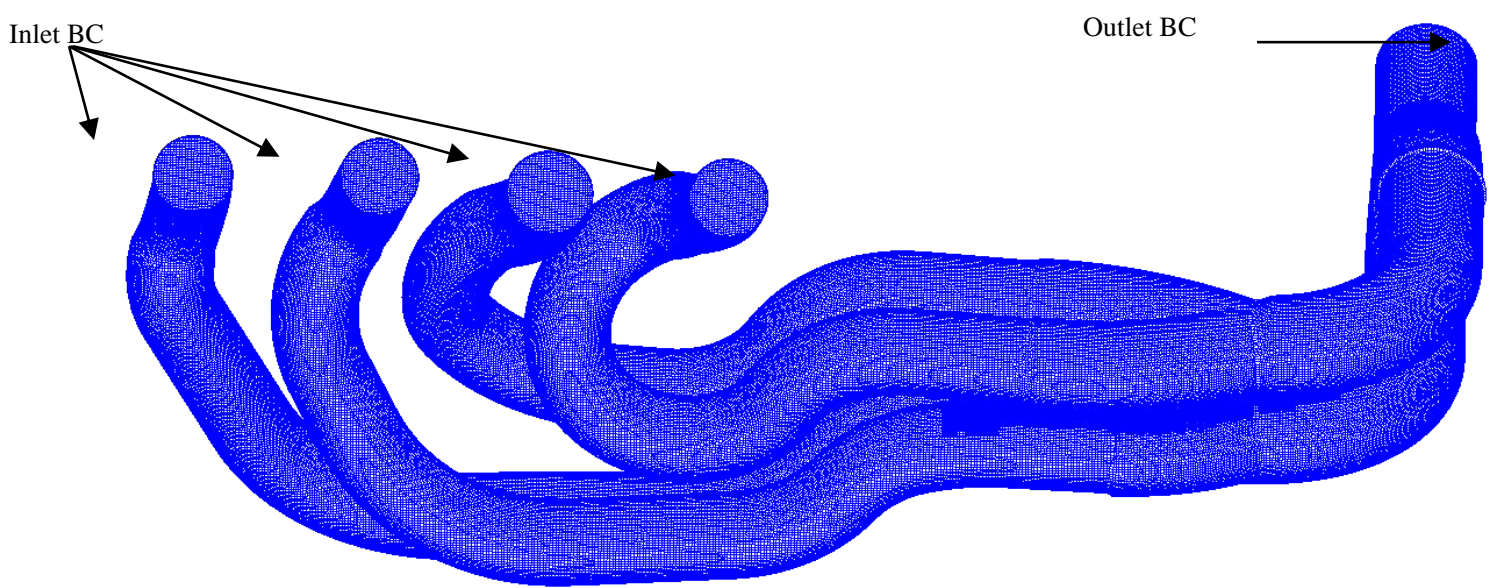

Fig. 5. Control volume mesh and the selections of the boundary conditions (BC)

\begin{tabular}{|l|c|}
\multicolumn{1}{|c}{ Table 1. Mesh parameter } \\
\begin{tabular}{|l|c|}
\hline \multicolumn{1}{|c|}{ Mesh information } & Value \\
\hline Number of nodes & 2066942 \\
\hline Number of surface faces & 394779 \\
\hline Number of edge elements & 0 \\
\hline Number of tria elements & 0 \\
\hline Number of quad elements & 0 \\
\hline Number of tet elements & 462 \\
\hline Number of hex elements & 1737050 \\
\hline Number of pyramid elements & 89711 \\
\hline Number of octa elements & 0 \\
\hline Number of prism elements & 174660 \\
\hline Number of other elements & 0 \\
\hline Total number of elements & 2001883 \\
\hline Surface area & 0.31953816606 \\
\hline Volume & 0.00297471268 \\
\hline
\end{tabular}
\end{tabular}

In addition, the wall temperature of an external pipe was set $\mathrm{Tw}=573 \mathrm{~K}$, heat transfer coefficient $(\mathrm{hc})=50 \mathrm{~W} / \mathrm{m} 2 / \mathrm{K}$ and ambient temperature $300 \mathrm{~K}$.

\section{NUMERICAL SIMULATION RESULTS}

\subsection{Flow properties}

Exhaust manifolds are a part of IC engines, it is used to collect and carry the exhaust gases away from the cylinder head and send it to the exhaust tail, with a minimum back pressure (Montenegro et al 2012). More so, the intake and compression strokes are one of the most significant processes which influences the behaviour of air flow structure inside cylinder, details in figure 6. Due to the high velocity inside the Internal Combustion Engine (ICE) during intake operation, all in cylinder flows are typically turbulent1. 
The best design of exhaust manifold and ducts produce a good condition needed for the fuel injection during the compression stroke. The exhaust gas was high in temperature at the exhaust pipe, especially at low engine rotation conditions because, there no catalyst or intercooler to absorb more pollutant or the heat in the race car system. In figure 7 The temperature profiles were obtained to identify irregularity for heat loss.

3D computational fluid dynamics (AVL Fire) was developed for the flow characteristic in the exhaust manifolds of the Honda CBR 600RR (PC $37)$ engine. the radiated noise plays an important role. In this research work we focus on this pulses noise, the pulsating flow in the duct system generates flow noise by vortex shedding and turbulence at geometrical discontinuities, figure 8 Shows pressure contour at the exhaust ducts (manifold) for each stroke at $8000 \mathrm{rpm}$.

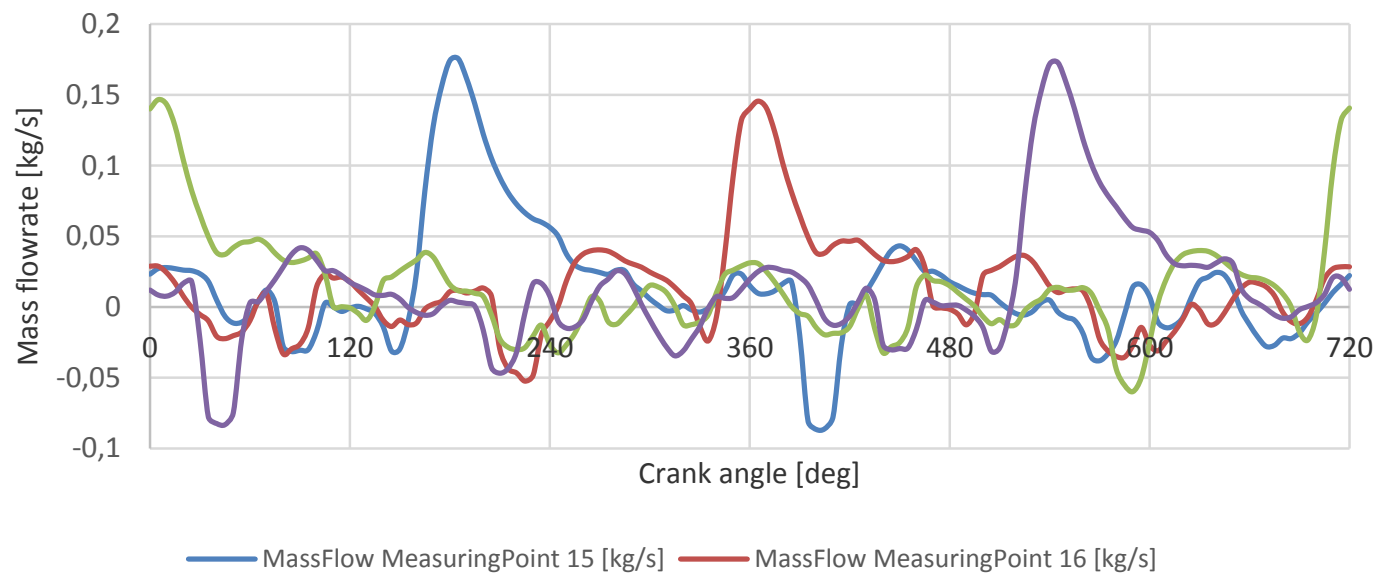

Fig. 6. Mass flowrate in $[\mathrm{kg} / \mathrm{s}]$ through exhaust manifold for complete engine cycle at $8000 \mathrm{rpm}$

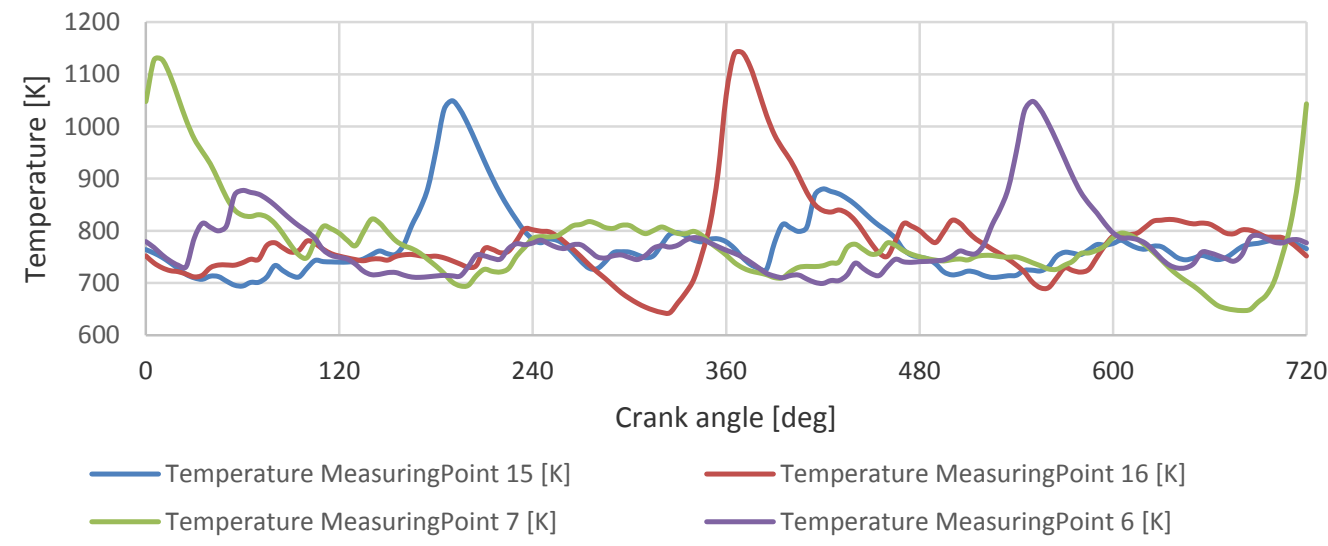

Fig. 7. Exhaust gas temperature in $[\mathrm{K}]$ for complete engine cycle at $8000 \mathrm{rpm}$

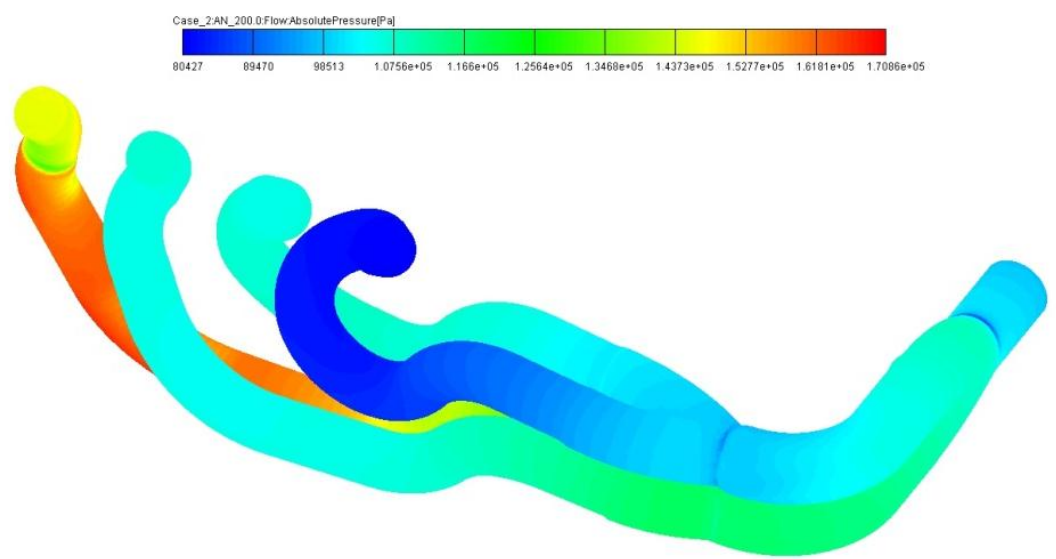

Fig. 8. Pressure contour in [Pa]; Min=80427, $\mathrm{Max}=1.7086 \mathrm{e}+05 \mathrm{~Pa}$ at $8000 \mathrm{rpm}$ 
The propagation properties of these pulses are influenced by the dimensions and acoustic absorption properties of the device structure in the exhaust line (muffler). In general, Noise generated by high velocity outlet flow can be reduced by letting a part of the flow go outside the main flow with a lower flow velocity, thus making the velocity difference between the outlet flow and the surrounding air smaller as shown in figure 9.

Both the bulk gas motion and the turbulence features of the flow are important to produce the homogeneity structure of gas flow come into muffler, in figure 10 The direction of flow vectors was monitored to identify swirl generation.

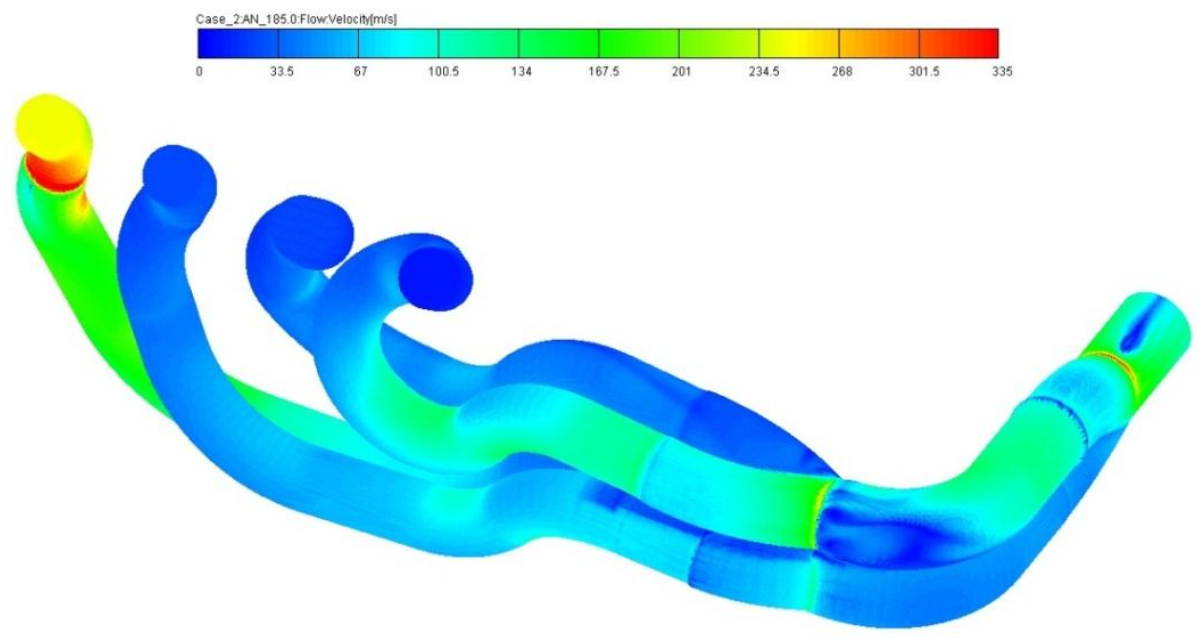

Fig. 9. Velocity contour in $[\mathrm{m} / \mathrm{s}]$; Min=0, Max=335 at $8000 \mathrm{rpm}$

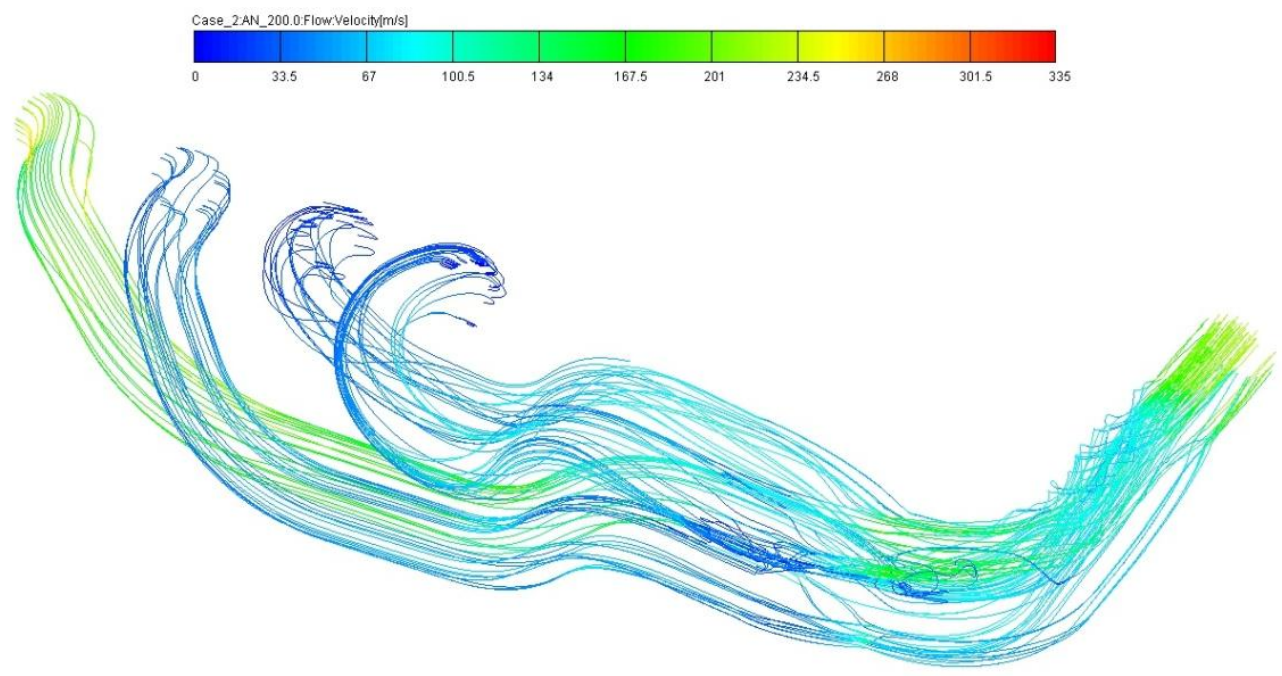

Fig. 10. Velocity streamline in $[\mathrm{m} / \mathrm{s}]$; Min=0, Max=335 at $8000 \mathrm{rpm}$

Engine being the power generating source continuously generates pressure waves during its working process. These pressure waves are nothing but the pulsating behavior of the exhaust gases. These exhaust gas pulses move due to a differential pressure, from the engine to the ambient atmosphere. These pulses when they interact with the atmosphere which is at a low pressure than the combustion gases. The exhaust orifice noise contributes to interior and exterior race car noise, As show in figure 11.

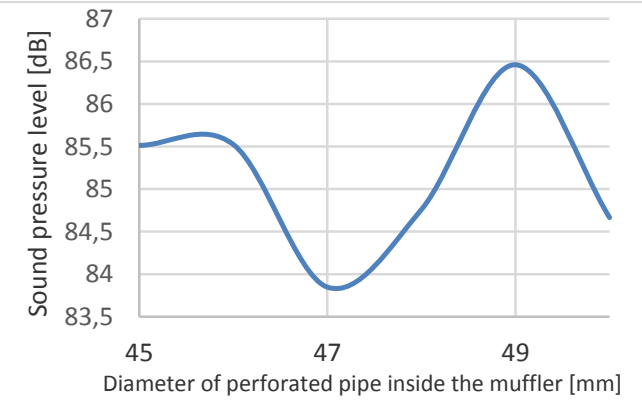

Fig. 11. The effect of diameter of perforated pipe inside the muffler $(\mathrm{PPiP})$ in $[\mathrm{mm}]$ on sound pressure level (SPL) in $\mathrm{dB}$ 
The order noise radiated from the orifice of the exhaust systems is caused by the pressure pulses generated by the periodic charging and discharging process and propagates to the open ends of the duct systems. As show in figure 12 The effect of diameter of hole of perforated pipe inside the muffler has been monitored.

\subsection{The effect of muffler size on the engine performance}

In figure 13 It is possible to find the optimum torque profile for Formula-Student race car and the effects of pipe length $(\mathrm{Lm})$ and diameter (Dm_out) of non-perforated outer pipe were clarified.

The muffler plays an important role in the performance of an engine system. Generally, a proper exhaust system design leads to reduce the fuel consumption and exhaust emissions. In today's world, major objectives of engine designers are to achieve the twin goals of best performance, in figure 14 Show the effects of muffler dimensions on the brake specific fuel consumption (BSFC).

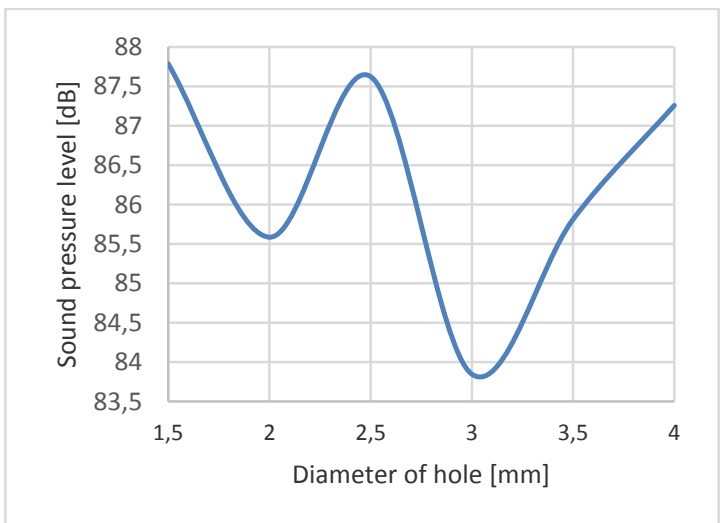

Fig. 12. The effect of diameter of hole of perforated pipe inside the muffler in [mm] on sound pressure level (SPL) in $\mathrm{dB}$

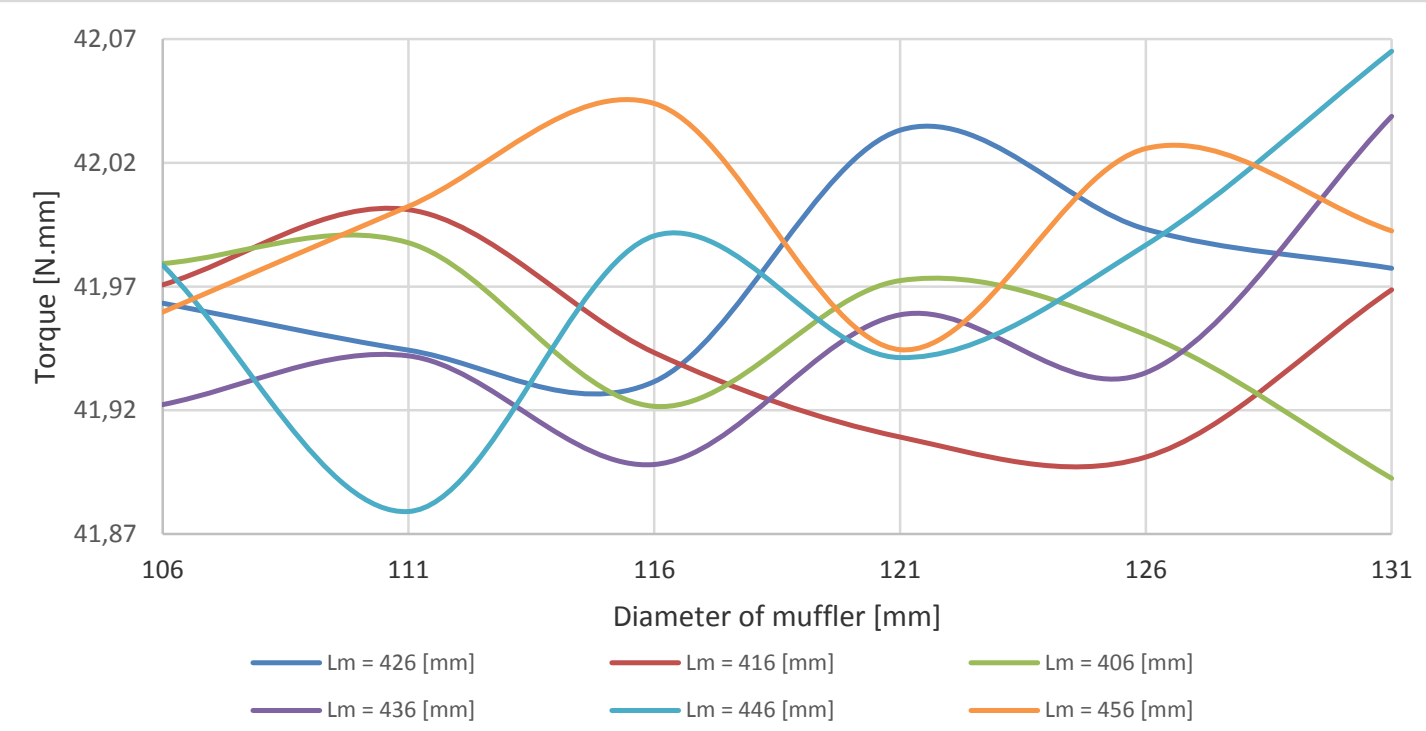

Fig. 13. Results of variation of pipe length $(\mathrm{Lm})$ and diameter (Dm_out) of non-perforated outer pipe (diameter of perforated inner pipe Dm_in $=47 \mathrm{~mm}, \mathrm{n}=2000 \mathrm{rpm}$ ) on FS engine torque

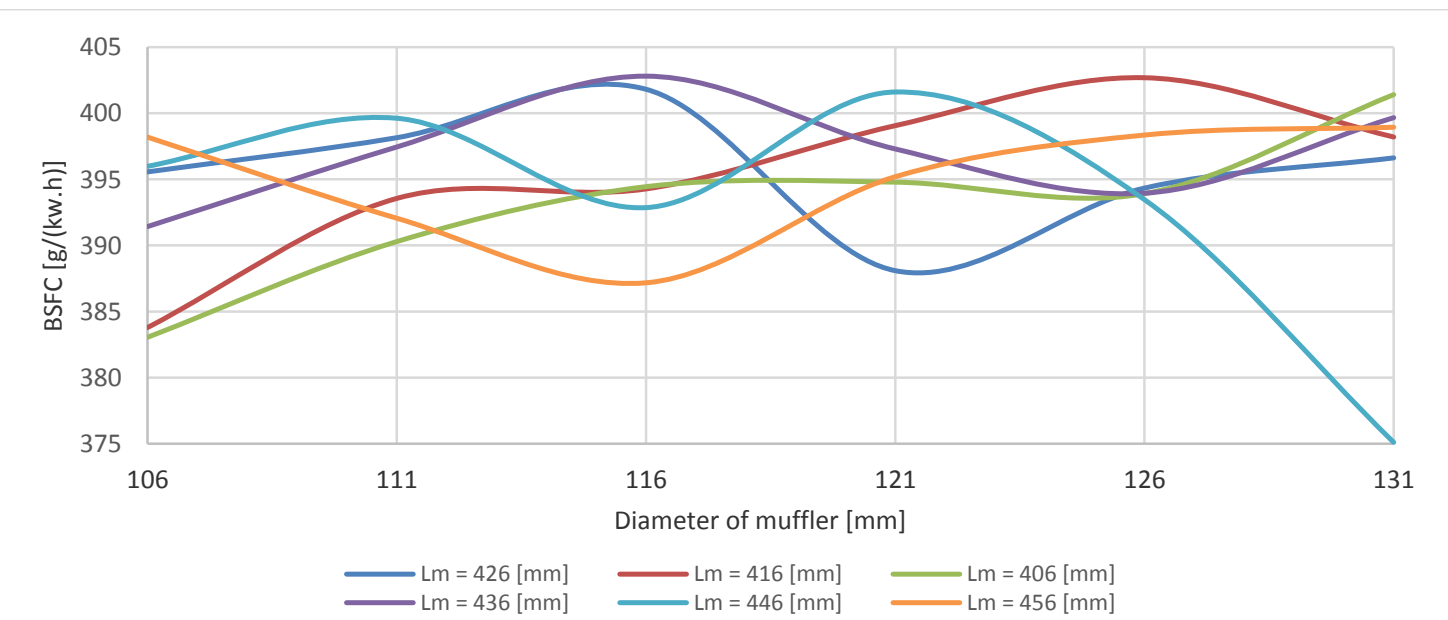

Fig. 14. Results of variation of pipe length $(\mathrm{Lm})$ and diameter (Dm_out) of non-perforated outer pipe (diameter of perforated inner pipe Dm_in $=47 \mathrm{~mm}, \mathrm{n}=2000 \mathrm{rpm}$ ) on FS engine BSFC 


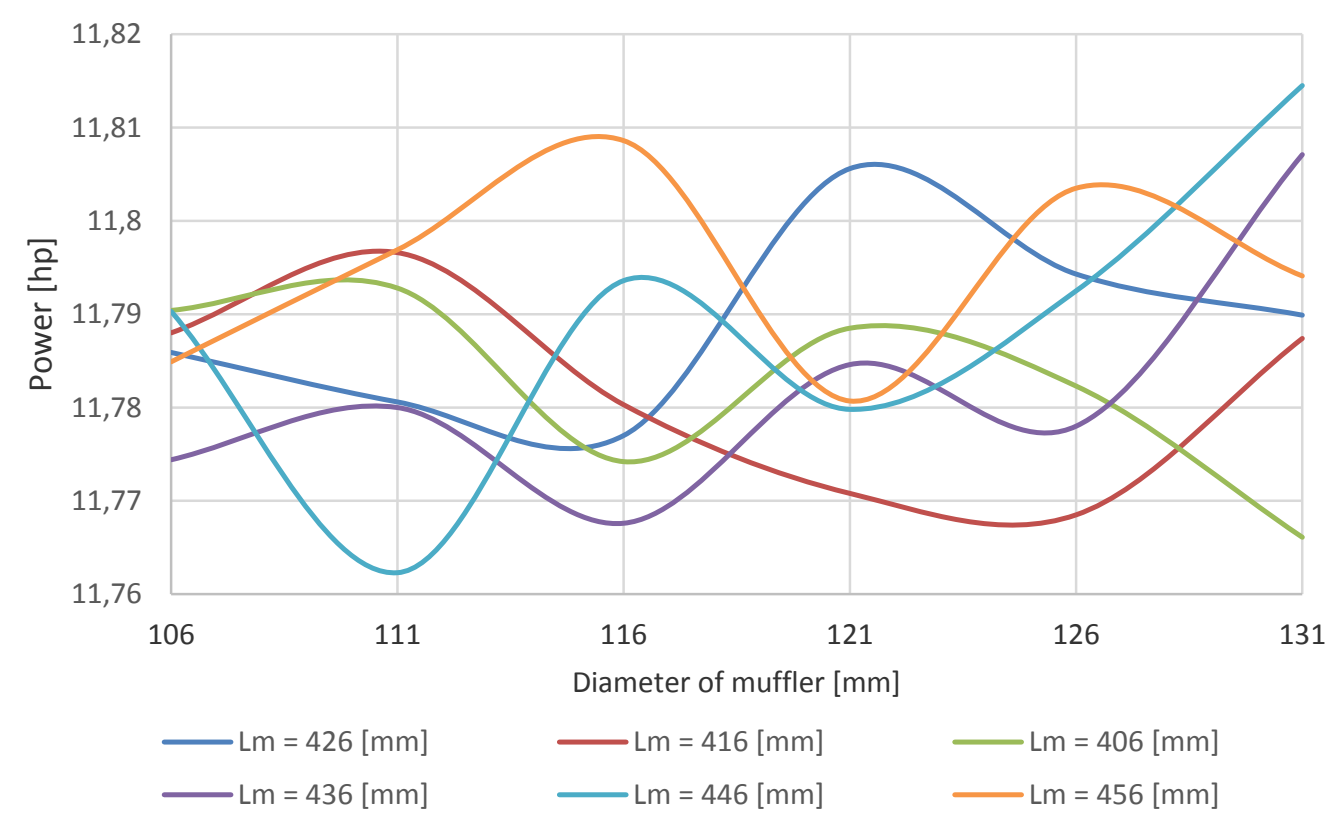

Fig. 15. Results of variation of pipe length ( $\mathrm{Lm})$ and diameter (Dm_out) of non-perforated outer pipe (diameter of perforated inner pipe Dm_in $=47 \mathrm{~mm}, \mathrm{n}=2000 \mathrm{rpm}$ ) on FS engine power output

Exhaust gas should also be led from the piston chambers to the exhaust system smoothly, to maximize the engine power especially at high engine rotation conditions, several analysis were made for muffler dimensions to reach optimum value, details are in figure 15 .

\section{CONCLUSIONS}

Fluid dynamics analysis was applied on the Formula-Student race car engine exhaust system Using Multilevel Numerical CFD Models. The results reveal that current design meet all functional requirements as mentioned above, namely adequate sound pressure level, minimal back pressure, space constraints and durability. Many possible design solutions were made to predict correct flow properties. Engine maximum power slightly increased from $11.76 \mathrm{hp}$ (with standard base manifold) to $11.81 \mathrm{hp}$ (with $\varnothing 35 \mathrm{~mm}$ diameter of manifold section) at $2000 \mathrm{rpm}$ and this could be more noticeable with high engine speed. Simulation revealed that gas restriction decreases engine power output also as a result, the lowest noise level while maintaining the power performance of the engine was achieved when Dm_out $=126 \mathrm{~mm}, \mathrm{Lm}=436 \mathrm{~mm}, \mathrm{Dm} \_$hole $=3$ $\mathrm{mm}$ and diameter of PPiP $=47 \mathrm{~mm}$. The numerical model could be used for further engine performance analysis and development.

\section{REFERENCES}

1. Cengel YA, Boles MA. Thermodynamics: An Engineering Approach (SI Units). 6th ed., Singapore: Mc Graw - Hill Higher Education. 2007.
2. Mohamad B. A review of flow acoustic effects on a commercial automotive exhaust system. Mobility and Vehicle Mechanics. 2019; 45(2):1-4. https://doi.org/10.24874/mvm.2019.45.02.01

3. Mohamad B. Szepesi G. Bolló B. Combustion Optimization in Spark Ignition Engines. MultiScience - XXXI. microCAD Scientific Conference, University of Miskolc-Hungary. 2017.

4. Mohamad B, Zelentsov A. 1D and 3D Modeling of Modern Automotive Exhaust Manifold. Journal of the Serbian Society for Computational Mechanics. 2019;13(1):80-91. https://doi.org/10.24874/jsscm.2019.13.01.05

5. Montenegro G, Onorati A. A Coupled 1D-multiD Nonlinear Simulation of I.C. Engine Silencers with Perforates and Sound- Absorbing Material. SAE Int. J. Passeng. Cars - Mech. Syst. 2009; 2(1):482-494, https://doi.org/10.4271/2009-01-0305.

6. Harrison MF, Stanev PT. A linear acoustic model for intake wave dynamics in I.C. engines," Journal of sound and vibration. 2004;269:361-387. https://doi.org/10.1016/S0022-460X(03)00196-2

7. Hanjalić K, Popovać M, Hadziabdić M. A Robust Near-Wall Elliptic-Relaxation Eddy-Viscosity Turbulence Model for CFD. Int. J. Heat Fluid Flow 2004, 25. 897-901.

8. Richard van Baashuysen FS. Internal Combustion Engine Handbook, Basics, Components, Systems and Perspectives. 2004, Canada: SAE International.

9. Bosch R. Gasoline engine management, WileyBlackwell; 3rd edition. 2009.

10. AVL BOOST v 2011.2. AVL BOOST Theory, Graz, Austria. 2011.

11. Mohamad B, Karoly J. Zelentsov A, Amroune S. A hybrid method technique for design and optimization of Formula race car exhaust muffler. International Review of Applied Sciences and Engineering 2020; 
11(2): $174-180$

https://doi.org/10.1556/1848.2020.20048.

12. Mohamad B, Karoly J, Zelentsov A. CFD Modelling of Formula Student Car Intake System. Facta Universitatis Series: Mechanical Engineering 2019; 18(1):153-163.

https://doi.org/10.22190/FUME190509032M.

13. Adumitroaie V, Ristorcelli JR, Taulbee DB. Progress in Favré-Reynolds stress closures for compressible flows. Physics of Fluids. 1999; 11:2696; https://doi.org/10.1063/1.870130.

14. Montenegro G, Torre A, Della, Onorati A, Fairbrother R, Elnemr Y, Dolinar A. Quasi-3D Acoustic Modeling of Common Intake and Exhaust Components. $19^{\text {th }}$ International Congress on Sound and Vibration. 2012; 3:2430-2437.

15. Montenegro G, Onorati A, Cerri T, Torre A. Della. A Quasi-3D Model for the Simulation of the Unsteady Flows in I.C. Engine Pipe Systems," SAE Technical Paper 2012-01-0675. https://doi.org/10.4271/201201-0675.

Received 2020-05-17

Accepted 2020-08-20

Available online 2020-08-24

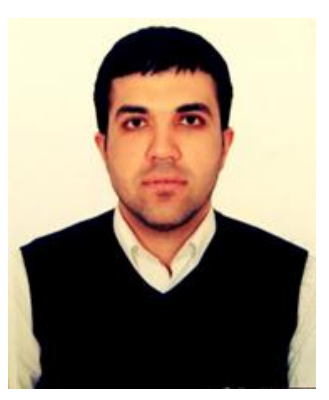

Barhm MOHAMAD, a researcher in the Faculty of Mechanical Engineering and Informatics, University of Miskolc. His research area is engine powertrain. Especially, he is interested in design and optimization of internal combustion engine parts using computational fluid dynamics. He has authored and co-authored more than 22 papers, mostly published in international journals or international conference proceedings and he is the coordinator of numerous projects funded by regional, national and EU grants.

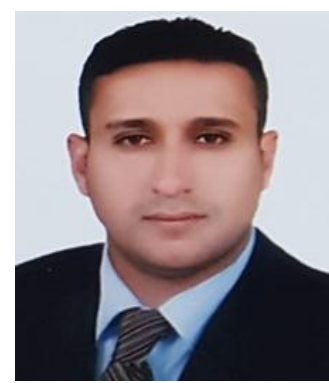

Mohammed Qasim ALI, a researcher in vocational department in ministry of education, Iraq. His research area is machine design. Especially, he is interested in damage identification techniques in composite materials.

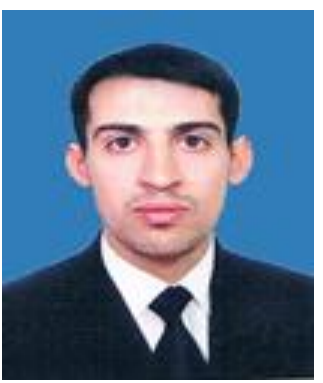

Hayder Ahmed

NEAMAH, attended the

Wuhan University of Technology from 2016 to 2019, majoring in Mechanical-Power Engineering, School of Automotive Engineering, Wuhan, China. $\mathrm{He}$ is currently a PhD Student in Thermal Power Program in University of Technology, Baghdad, Iraq. His research interests on the engine emissions, implementing computational fluid dynamics solvers in internal combustion engine and biofuel.

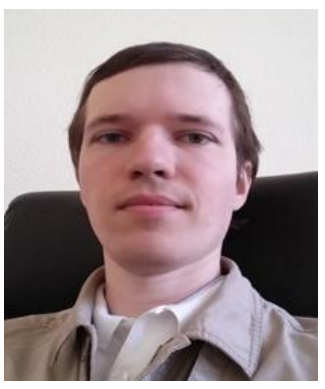

Andrei ZELENTSOV, an Associate Professor of Piston Engine Department, Bauman Moscow State Technical University. The research areas are combustion and heat transfer processes in cylinder, improvement of ecological and effective parameters of piston engines.

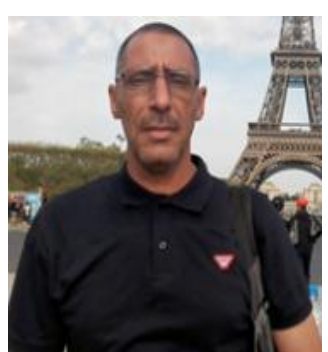

Salah AMROUNE, was born in M'sila, Algeria. He received from M'sila University of Algeria his Mechanical state engineer diploma in 1992 and doctorate degree in mechanical engineering from the 08 Mai 1945 Guelma University of Algeria in 2016. His research activities are based on the characterization of natural fibers and bio composites, Plus, modelling and numerical simulation of CNC machining. 